\title{
METFORMIN ATTENUATES THIOACETAMIDE INDUCED HEPATOTOXIC EFFECTS IN RATS
}

\author{
BY \\ Seba H. Abd El-Hady, Ali A. Moustafa, Ameen M. Sekkinah, Soad L. Kabil
}

FROM

Department of pharmacology, Faculty of Medicine, Zagazig University.

\begin{abstract}
Thioacetamide (TAA) is a well known hepatototoxic chemical that is used to induce liver cirrhosis similar to that occurred in human. This study was performed to investigate the possible protective effect of metformin against deleterious effects induced by thioacetamide in rat livers and to find out the possible mechanisms of action. Male rats were divided into 4 groups control group, TAA group received 300mg/L in drinking water for 12 weeks, metformin group received $50 \mathrm{mg} / \mathrm{kg} / \mathrm{day}$ by gavage for 12 weeks and co- treated group that received metformin $50 \mathrm{mg} / \mathrm{kg} / \mathrm{day}$ by gavage for 12 weeks in addition to TAA in the same previously mentioned dose for the same duration of time and started from the first day of metformin. The rats were weighted and euthanized. Liver tissues and blood samples were collected for estimation of key oxidative stress markers, liver enzymes and pro-inflammatory cytokine (TNF- $\alpha$ ). The results showed that TAA induced massive functional and structural damage of the liver. Metformin treated rats significantly attenuated TAA induced changes in both liver function and structure with reduction in rises of malondialdehyde (MDA) and superoxide dismutase (SOD) levels in liver tissue with reduction in serum levels of TNF- $\alpha$. The liver weights (LW) and the liver/body weight ratios (LW/BW) in thioacetamide rats had significantly increased compared to the control rats. Metformin had significantly reduced liver weights and the liver/body weight ratios compared to thioacetamide rats. On conclusion: metformin attenuates the deleterious effects of thioacetamide on liver tissue and exhibits hepatoprotection against these effects through inhibition of peroxidation, inflammation and oxidative stress and enhanced antioxidant status in rat liver tissues suggesting the potential efficacy of metformin as an addition hepatoprotective, anti-inflammatory and anti-hepatotoxic agent in treatment of liver toxicity.
\end{abstract}

Keywords: Metformin, Thioacetamide, Oxidative stress, Hepatoprotection. 


\section{Introduction}

Thioacetamide (TAA) is a widely used sulfur-containing compound both in the laboratory and in various technical applications, which is also known as thioacetamidic acid or acetothiomide " $\mathrm{CH}_{3} \mathrm{CSNH}_{2}$ " (Al-Attar, 2011). The widespread use of TAA is unavoidably and the primary routes of potential human exposure are inhalation and dermal contact. Also, consumer exposure to TAA has occurred from contact with products where TAA was used as a solvent. Occupational exposure may occur during production and packaging of the chemical as a laboratory reagent (Huang et al, 2007). Thioacetamide (TAA) is a carcinogenic and a hepatotoxic agent that is also used for the experimental induction of hepatic lesions in rats (mainly, through administration of large doses in the drinking water) that develops liver cirrhosis similar to human cirrhosis (Fernández et al, 2005). TAA-induced liver cirrhosis is observed to be associated with lipid peroxidation and depletion of antioxidants (Low et al, 2004). Accordingly reduction of oxidative stress appears to be helpful for the regression of fibrosis and cirrhosis, and the use of radical scavengers and antioxidants had been reported to inhibit development of cirrhosis (Aydin et al, 2010). The biguanide, metformin, is the most widely prescribed insulin sensitizer used for therapeutic management of type 2 diabetes, exerts most of its metabolic action on the liver (Palomba et al., 2009). The primary action of metformin is suppression of hepatic glucose production and the enhancement of peripheral glucose uptake; therefore, it normalizes the plasma glucose levels without any stimulation of insulin production (Zhou et al., 2001). Metformin also found place in the treatment of many clinical diseases like polycystic ovarian syndrome, obesity, fatty liver, protection against cardiac hypertrophy \& myocardial infarction (Joshi, 2005). There are many studies reported that metformin, commonly used anti-diabetic drug, reduce lipid peroxidation and enhance the anti-oxidant defence system activity as reported by Faure et al, (1999) and Khouri et al, (2004). Metformin prevents oxidative stress-induced death in several cell types through a mechanism that attenuates the mitochondrial permeability transition pore (PTP) (Jacotot et al. 1999) into the cytoplasm to initiate apoptosis in a caspasedependent or caspase-independent manner.

\section{Materials and Methods}

\section{Animals}

Forty eight male Wister albino rats weighing 180-200 gm/each were used. They were obtained from Zagazig Faculty of Veterinary Medicine- animal unit. All experiments in our study were performed in accordance with the guidelines for Animal Research from the National Research Centre, Cairo, Egypt. Animals received a standard diet and water, ad labitum, and were housed in Zagazig Faculty of Medicine Animal House with 12 hours light/dark cycle. Animals were left for a week before starting the study to accommodate the environment in the animal house. The study protocol was approved by the ethical committee at Zagazig University. 


\section{Drugs and chemicals}

Metformin hydrochloride, powder was purchased from Egyptian International Pharmaceutical Industries Company (Egypt). Thioacetamide (TAA) powder was purchased from Sigma (USA).

\section{Experimental design}

Rats were randomly divided into 4 groups (12 rats each). Group 1 received distilled water and served as negative control. Group 2 received thioacetamide (TAA) $300 \mathrm{mg} / \mathrm{L}$ of drinking water " $0.03 \%$ solution for 12 weeks. Group 3 received metformin $\mathrm{Hcl} 50 \mathrm{mg} / \mathrm{kg} /$ day orally by gavage for 12 weeks. Group 4 rats were treated with metformin Hcl $50 \mathrm{mg} / \mathrm{kg} /$ day orally by gavage plus TAA $300 \mathrm{mg} / \mathrm{L}$ of drinking water " $0.03 \%$ solution for 12 weeks. At the end of the work, the body weight was estimated for all rats and blood samples were withdrawn from the retro-orbital sinus of rats. Serum was separated by centrifugation at $3000 \mathrm{rpm}$ for $15 \mathrm{~min}$ and divided into small aliquots that were stored at $-80^{\circ} \mathrm{c}$. Animals were euthanized by $\mathrm{CO} 2$ asphyxiation and livers were rapidly excised, washed with saline and weighed in order to estimate liver/ body weight ratio. The liver tissue in each animal in each group was sub-divided into two equal parts; one was subjected to homogenization while the other one was for histopathological study. The livers were washed with ice-cold saline, blot dried and then used for estimation of malondialdehyde (MDA) and superoxide dismutase (SOD) contents. In order to perform such assays, the liver samples were embedded in phosphate buffer $(50 \mathrm{mmol} / \mathrm{L}, \mathrm{pH} 6)$ at 5 -times the tissue volume and processed in a Potter-Elvehjem homogenizer. The supernatant homogenate was aliquoted and frozen at $-80{ }^{\circ} \mathrm{C}$ until be used in the assays (Helewski et al., 2010).

\section{Biochemical and histological assays}

The serum samples were used for estimation of the levels of Alanine amino transferase (ALT) \& Aspartate amino transferase (AST), alkaline phosphatise (ALP), gamma glutamyl transferase (GGT) and Total proteins using commercial reagent kits. Oxidative stress parameters in tissue including malondialdehyde (MDA) levels were determined by using Colorimetric method described by Ohkawa et al, (1979) and super oxide dismutase (SOD) levels were determined according to Colorimetric method described by Nishikim et al, (1972). Representative slices from liver were taken from the animals and fixed in buffered formalin (10\%). Paraffin embedded sections $(4 \mu \mathrm{m}$ thickness) were stained using: H \& E by the method of Hirsch et al, (1997) and Rahn, (2001), Mallory Trichrome stain (MT) for examination of the collagen of connective tissue (Lamar, 2011) and Periodic acid-Schiff (PAS) used to detect polysaccharides such as Glycogen (Carson \& Haladik, 2009). The slides were examined by light microscope to set out a numerical score amenable to statistical analysis. 


\section{Statistical analysis}

The results were expressed as mean + Standard Error (SE) of 6 rats per group to evaluate variations in data, a one-way analysis of variance (one-way ANOVA) was performed followed by a Student's t-test using the Bonferroni correction for multiple comparisons; when the analysis indicated the presence of a significant difference, the means were compared with the Duncan test. Significance was accepted at $p \leq 0.05$. Statistical Package of Social Sciences (SPSS) computer software (version 14) was used to carry out the statistical analysis.

\section{Results}

Rats received thioacetamide showed significant reduction in liver function as illustrated by remarkable increases in serum levels of ALT (169.4\%), AST (369\%), ALP (191.7\%), GGT (620\%), plasma globulin (140.4) with significant reduction in serum albumin (76.9\%) and Albumin/Globulin ratio (55\%) compared to values in control group (table-1). Metformin plus TAA treated rats had significant reductions in serum levels of ALT (82.45\%), AST (58.5\%), ALP (78.8\%), GGT (25\%) and plasma globulin (83\%) with significant increase in serum albumin (123.5\%) and Albumin/ Globulin ratio (148.6\%) compared to thioacetamide rats (table-1). Metformin treated rats showed no significant difference in the same parameters in comparison with the control group but these values are significantly reduced compared to metformin plus TAA treated rats. Also, rats of thioacetamide group showed significant increase in serum TNF- $\alpha$ level $(476.36 \%)$ compared to control group. Co-administration of TAA and metformin had significantly reduced serum TNF- $\alpha$ level (38.3\%) compared to TAA rats (table-1). The values of TNF- $\alpha$ in metformin treated rats had significantly reduced in comparison with co-administration of metformin and TAA (table-1).

Table (1): Effect of metformin treatment on liver function parameters and TNF- $\alpha$ $(\mathrm{n}=12)$ :

\begin{tabular}{|l|c|c|c|c|}
\hline \multicolumn{1}{|c|}{ Parameters } & Control & Thioacetamide & $\begin{array}{c}\text { Metformin and } \\
\text { thioacetamide }\end{array}$ & $\begin{array}{c}\text { Metformin } \\
\text { treated }\end{array}$ \\
\hline ALT (U/L) & $37.00 \pm 1.36^{\mathrm{A}}$ & $62.76 \pm 3.81^{\mathrm{B}}$ & $51.67 \pm 1.52^{\mathrm{C}}$ & $40.67 \pm 1.31^{\mathrm{A}}$ \\
\hline AST (U/L) & $43.83 \pm 3.45^{\mathrm{A}}$ & $161.83 \pm 3.11^{\mathrm{B}}$ & $49.67 \pm 3.94^{\mathrm{C}}$ & $49.33 \pm 1.78^{\mathrm{A}}$ \\
\hline ALP (U/L) & $111.83 \pm 3.54^{\mathrm{A}}$ & $214.33 \pm 4.28^{\mathrm{B}}$ & $168.83 \pm 7.63^{\mathrm{C}}$ & $116.16 \pm 3.16^{\mathrm{A}}$ \\
\hline GGT (U/L) & $1.50 \pm 0.22^{\mathrm{A}}$ & $9.30 \pm 0.61^{\mathrm{B}}$ & $2.33 \pm 0.42^{\mathrm{AC}}$ & $1.50 \pm 0.22^{\mathrm{A}}$ \\
\hline Total proteins (g/dl) & $7.43 \pm 0.22^{\mathrm{A}}$ & $7.73 \pm 0.06^{\mathrm{B}}$ & $7.75 \pm 0.11^{\mathrm{A}}$ & $7.63 \pm 0.15^{\mathrm{A}}$ \\
\hline Plasma albumin (g/dl) & $4.26 \pm 0.02^{\mathrm{A}}$ & $3.28 \pm 0.05^{\mathrm{B}}$ & $4.05 \pm 0.04^{\mathrm{C}}$ & $4.36 \pm 0.06^{\mathrm{A}}$ \\
\hline Plasma globulin(g/dl) & $3.17 \pm 0.2^{\mathrm{A}}$ & $4.45 \pm 0.07^{\mathrm{B}}$ & $3.7 \pm 0.14^{\mathrm{C}}$ & $3.27 \pm 0.13^{\mathrm{A}}$ \\
\hline $\begin{array}{l}\text { Plasma albumin/globulin } \\
\text { (g/dl) }\end{array}$ & $1.34 \pm 0.09^{\mathrm{A}}$ & $0.74 \pm 0.03^{\mathrm{B}}$ & $1.1 \pm 0.08^{\mathrm{C}}$ & $1.33 \pm 0.05^{\mathrm{A}}$ \\
\hline TNF- $\alpha$ & $14.19 \pm 0.4^{\mathrm{A}}$ & $69.8 \pm 0.76^{\mathrm{B}}$ & $30.86 \pm 0.88^{\mathrm{C}}$ & $13.11 \pm 0.4^{\mathrm{A}}$ \\
\hline
\end{tabular}

- Values represent means \pm standard error (SE). 
- Values in the same column without common superscript capital letters are significantly $(\mathrm{p}<0.05)$ different.

- $\mathrm{n}$ : number of rats in each group.

Figure -1, illustrates significant increases in oxidative stress parameters malondialdehyde and superoxide dismutase in thioacetamide received rats liver tissues compared to control group. Combined administration of metformin and thioacetamide for 12 weeks had significantly reduced malondialdehyde and superoxide dismutase compared to thioacetamide received rats.
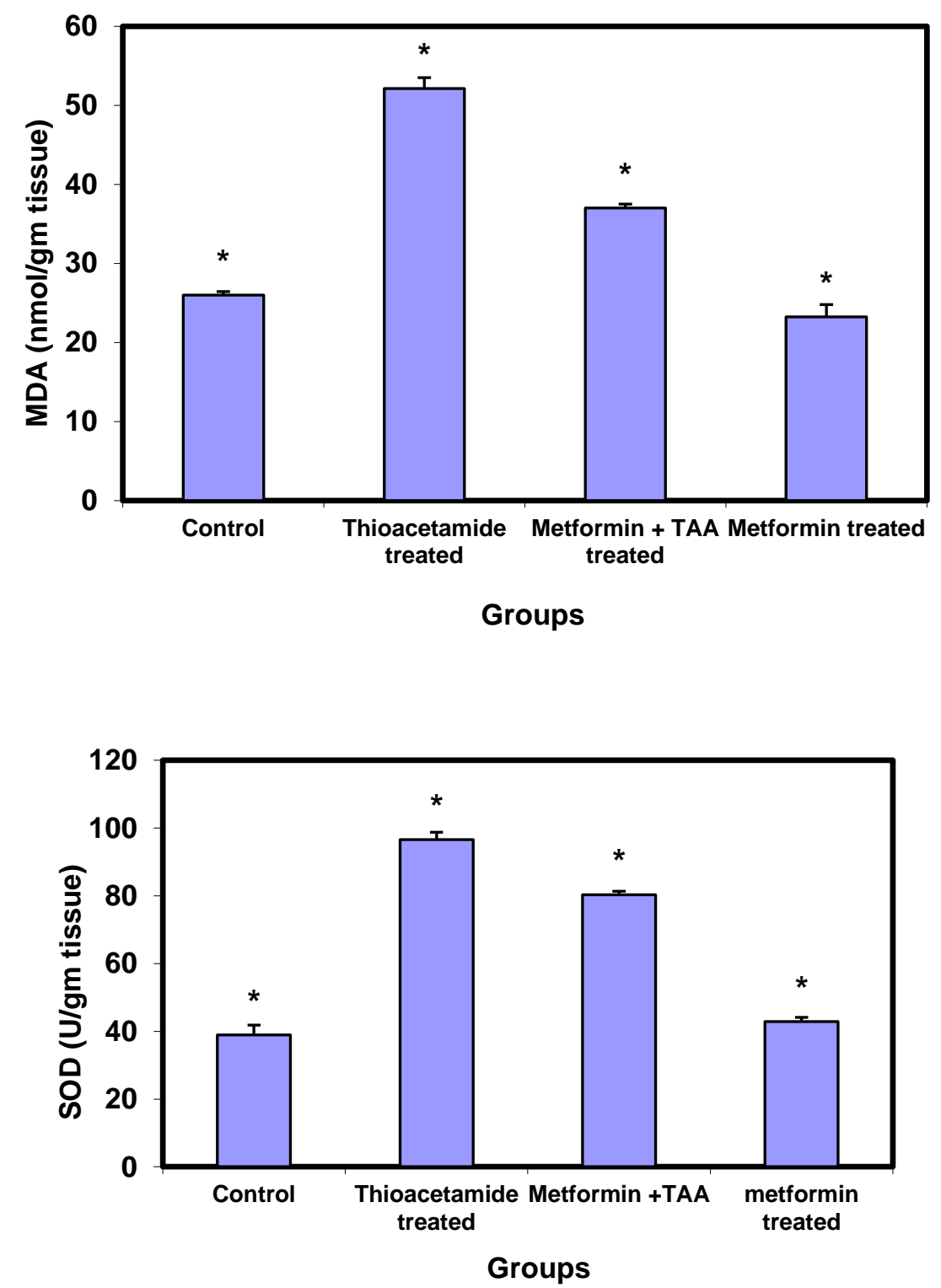

Figure 1. Effect of metformin $(50 \mathrm{mg} / \mathrm{Kg} /$ day $)$, thioacetamide $(300 \mathrm{mg} / \mathrm{L})$ and their combination for 12 weeks on MDA and SOD levels in liver tissue. Data shown in mean indices $( \pm$ SEM) from six rats / group. $* \mathrm{p}<0.05(\mathrm{P}<0.05)$ significantly different. 
Figure 2 illustrates significant reduction in the body weight (BW) of rats received thioacetamide ( $300 \mathrm{mg} / \mathrm{L}$ in drinking water for 12 weeks) compared to the control group. However, the values of body weights in metformin plus TAA treated group (50 mg/kg/day orally for 12 weeks) had significantly increased compared to thioacetamide group (figure-2). The liver weights (LW) and the liver/body weight ratios (LW/BW) in thioacetamide rats had significantly increased compared to the control rats (figure-2). In metformin plus TAA treated rats, liver weights and the liver/body weight ratios had significantly reduced compared to thioacetamide rats (figure-2).
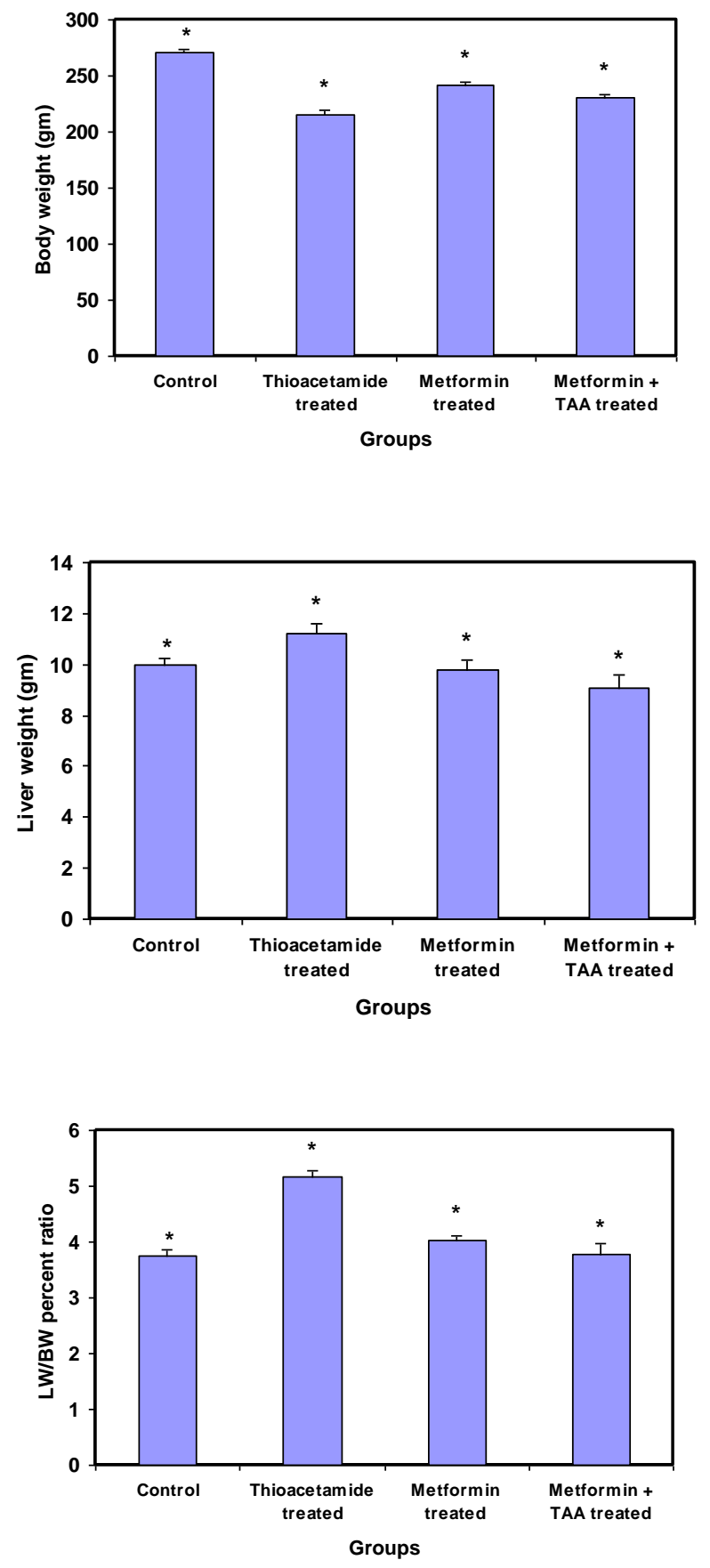
Figure 2. Effect of metformin $(50 \mathrm{mg} / \mathrm{kg} / \mathrm{day})$, Thioacetamide $(300 \mathrm{mg} / \mathrm{L})$ and their combination for 12 weeks on BW (gm), LW (gm) and LW/BW ratio. Data shown in mean indices $( \pm$ SEM) from six rats / group. $* \mathrm{p}<0.05(\mathrm{P}<0.05)$ significantly different.

\section{Histopathological changes in liver}

Liver sections of the control rats showed normal hepatic architecture, hepatocytes are arranged in plates and radiating from the central vein (figure 3a). These polygonal cells showed traces of collagen fibres centred on the central vein, acidophilic cytoplasm and rounded nuclei (figure $3 b$ ) with strong Periodic Acid Schiff (PAS) positive reaction (figure $3 \mathrm{c}$ ). Examination of liver sections of rats received thioacetamide $(300 \mathrm{mg} / \mathrm{L})$ revealed loss of lobular architecture, regenerating lobules (figure3d) with necrotic changes and bridging fibrosis (figure $3 \mathrm{e}$ ) and weak PAS positive reaction at the site of bridging necrosis (figure $3 \mathrm{f}$ ). Liver sections from metformin plus TAA treated rats showed improvement of the histological changes detected in thioacetamide rats. Liver sections of this group had mild lobular inflammation (figure $3 \mathrm{~g}$ ), minimal fibrosis surrounding the central vein (figure $3 \mathrm{~h}$ ) with strong positive PAS reaction (figure $3 i$ ).

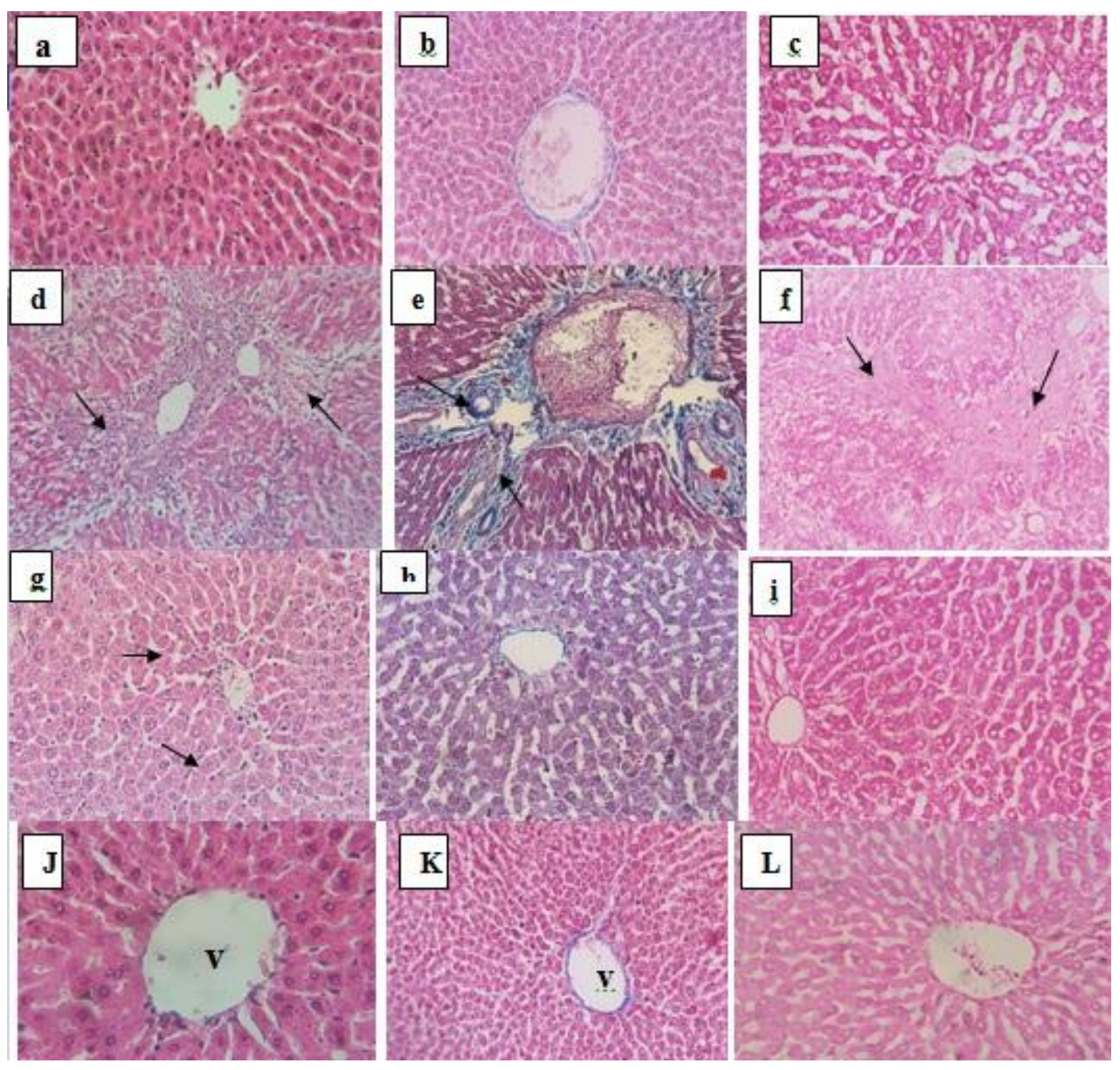


Figure 3. Representative liver sections of different groups.(a) control group showing the hepatocytes arranged in plates and radiating from the central vein (H\&E× 200),(b) control group showing traces of collagen fibers centred on the central vein (blue colour) (Mallory trichrome $\times 100$ ). (c) Liver section of control group with strong PAS positive reaction $(\mathrm{PAS}) \times 100$. (d) Liver section of TAA group shows severe necrosis with bridging fibrosis "B.F" and cirrhosis (H\&E× 200). (e) Liver section of TAA group shows massive fibrosis (blue colour) in the portal area "M.T $\times 200 "$ ". (f) Liver section of TAA group showing weak PAS positive reaction at the site of bridging necrosis "PAS $\times$ 200". (g) Liver section of metformin plus TAA treated group showing mild lobular inflammation \& minimal necrosis $(H \& E \times 200)$. (h) Liver section of metformin plus TAA treated group showing minimal fibrous tissue surrounding central vein (M.T. $\times$ 200). (i) Liver section of metformin plus TAA treated group showing strong PAS positive reaction of hepatocytes (PAS $\times 200)$. $(\mathbf{J})$ Liver section of metformin treated group showing the hepatocytes radiating around central vein in plates (H\&E× 400). (K) Liver section of Liver section of metformin treated group showing traces of collagen fibres around central vein (Mallory trichrome $\times 200$ ). (L) Liver section of metformin treated group with strong PAS positive reaction of hepatocytes $(\mathrm{PAS} \times 200$ ).

\section{Discussion}

The present study demonstrated that administration of TAA caused elevation in the serum ALT, AST, ALP, and GGT levels with reduction in plasma albumin and albumin/globulin ratio compared with control group, metformin group and metformin plus TAA group. This is in agreement with previous data (Abul et al, 2002; Alshawash et al 2011) which could be taken as an index of liver damage. In our study, the rise in AST, ALT, ALP and GGT levels induced by TAA administration was significantly reduced by administration of metformin suggesting that metformin protective activity might be due to its effect against cellular leakage and loss of functional integrity of the cell membrane in hepatocyte. The increase in AST, ALT, ALP and GGT serum levels of rats received TAA might be due to increased permeability of plasma membrane with cellular necrosis leading to leakage of the enzymes to the blood stream (Al-shawash et al, 2011; Amin et al, 2012) and this reflects the stress condition of the TAA treated animals. Al-shawash et al, (2011) and Amin et al, (2012) interpreted the elevated serum levels of AST and ALT as a result of the hepatocytes damage and alterations in the membrane permeability indicating the severity of hepatocellular insult induced by TAA, which is in accordance with previous reports of Abul et al, (2002). Elevation of serum levels of ALP, and GGT of TAAreceived rats suggesting the presence of cholestatic hepatic damage as reported by Park et al,( 2010) and Al-Attar, (2011) who attributed these elevations to inflammatory oedema which causes bile flow obstruction leading to impairment of their biliary secretion (Gill, 2013). In TAA treated rats, the plasma albumin level and the albumin/globulin ratio (A/G ratio) decreased compared with all other groups which is in accordance with Park et al, (2010) and Al-Attar, (2011) who attributed these 
reductions to the degradation of proteins by TAA toxic compounds and impairment of liver synthesis activity due to chronic toxicity induced by TAA. In our study, administration of metformin combined with TAA decreased the serum levels of TNF- $\alpha$ compared with TAA alone, this result is in agreement with previous work by (Missima, et al., 2009) who mentioned that TAA administration to rats submitted to chronic stress stimulated pro inflammatory cytokines including TNF- $\alpha$. In our study, administration of metformin to animals caused decrease in the levels of TNF- $\alpha$ compared with TAA group, this result is in agreement with previous work by Koh et al., 2014 who stated that metformin inhibited interleukin-8 ( IL-8) induction in mice colon cells stimulated with TNF- $\alpha$. Administration of metformin reduced the severity of dextran sulphate sodium-induced colitis. In the present study TAA-treated rats showed elevated levels of MDA and SOD in liver homogenates which reduced by treatment with metformin. The high level of lipid peroxidation marker MDA in TAA treated rats is a reflection of insufficiency of antioxidant defences in combating ROS-mediated damage (Amin et al, 2012). Lipid peroxidation impairs cell membrane fluidity and alters the activity of membrane-bound enzymes and receptors resulting in membrane malfunction. SOD catalyzes the dismutation of superoxide radical to hydrogen peroxide $(\mathrm{H} 2 \mathrm{O} 2)$, although SOD is an antioxidant enzyme, but its over- expression is actually harmful to cells. The toxic effect of ROS observed in many cells with over-expressed SOD has been linked to elevated levels of $\mathrm{H} 2 \mathrm{O} 2$ and accompanying oxidative damage following hydroxyl radical formation. The implication for SOD up-regulation is that there would be high turnover of H2O2 (Erejuwa et al, 2010). In the present study, the elevations in liver weight and liver weight/body weight ratio in TAA treated rats could be attributed to both of the inflammatory process, and the decrease in body weight secondary to the liver injury (Galisteo et al, 2006; Park et al, 2010). Also, the increase in LW/BW ratio is attributed to the up-regulation of the hepatocyte activity (hepatocyte proliferation) in response to the exposure to TAA toxicity (Amin et al, 2012). Co-administration of metformin with TAA reduced liver weight and LW/BW ratio and this could be attributed to the lower levels of nutrient absorption, energy utilization, and metabolic efficiency as the major factors affecting the inability of the rats to gain weight after being exposed to TAA (Madani et al, 2008). TAA treated rats showed hepatocellular necrosis in the peri-venous areas of the liver acini and Glycogen depletion mainly in the centrolobular area with weak Periodic Acid Schiff (PAS) positive reaction, this could be explained by the inability of degenerating liver cells to synthesize or store glycogen (Riddell, 1982; Muriel et al, 1993). Treatment with metformin reduced hepatocellular inflammatory reaction and necrotic changes induced by TAA and this is in agreement with Hadi et al, 2012 who stated that metformin by its ability to inhibit Janus kinases (JNK) activation that inhibit cellular apoptosis pathway. Furthermore, metformin attenuates the generation of oxygen reactive species and inhibits the opening of the mitochondrial membrane permeability transition pore activated by cytosolic $\mathrm{Ca}^{2+}$ and reactive oxygen species (ROS), thereby prevents necrotic processes. On conclusion: metformin attenuates the deleterious effects of thioacetamide on liver tissue and exhibits 
hepatoprotection against these effects through inhibition of peroxidation, inflammation and oxidative stress and enhanced antioxidant status in rat liver tissues suggesting the potential efficacy of metformin as an addition hepatoprotective, anti-inflammatory and anti-hepatotoxic agent in treatment of liver toxicity.

\section{Declaration of interest}

The authors report no conflict of interests. The authors alone are responsible for the content and writing of the paper.

\section{REFERENCES}

Abul H., Mathew T.C., Dashti H.M., and Al-Bader A. (2002): Levels of superoxide dismutase, glutathione peroxidase and uric acid in thioacetmaide induced cirrhotic rats. Anat Histol Embryol. 31: 66-71.

Al-Attar A.M. (2011): Hepatoprotective influence of vitamen C on thioacetamideinduced liver cirrhosis in wister male rats. Journal of pharmacology and toxicology. 6 (3): 218-233.

Alshawsh M.A., Abdullah M.A., Ismail S. and Amin Z.A.(2011): Hepatoprotective effects of Orthosiphon stamineus extract on thioacetamide-induced liver cirrhosis in rats. Evidence based Complementray and Alternative Medicine. 2011:1-6.

Amin Z.A., Bilgen M., Alshawsh M.A., Ali H.M., Hadi A.A., and Abdulla M.A. (2012): Protective role of Phyllanthus niruri extract against thioacetamide-induced liver cirrhosis in rat model. Evidence-Based Complementary and Alternative Medicine. 2012, 1-9.

Aydin A., Kusku-Kiraz Z., Dogru-Abbasoglu S., Gulluoglu M., and Uysal M. (2010): Effect of carnosine against thioacetamide-induced liver cirrhosis in rat. Peptides. 31:67-71.

Carson F.L. and Haladik C. (2009): Hisotecnology: A self-instructional text $\left(3^{\text {rd }}\right.$ edition). Hong Kong: Americaian society for clinical pathology 137-139 (ISBN 978-0-89789-581-7).

Erejuwa O., Sulaiman S.A., Abdul Wahab M.S., Salam S.K., Salleh M.S. and Gurtu S. (2010): Antioxidant Protective Effect of Glibenclamide and Metformin in Combination with Honey in Pancreas of Streptozotocin- Induced Diabetic Rats. Int J Mol Sci. 11: 2056-2066.

Faure P., Rossini E., Wiernsperger N., Richard M.J., Favier A. and Halimi S. (1999): An insulin sensitizer improves the free radical defense system potential and insulin sensitivity in high fructose-fed rats. Diabetes. 48 (2):353-357. 
Fernández I., Fontana L., Gil A., Ríosc A. and Torres M.I. (2005): Dietary supplementation with monounsaturated and long-chain polyun- saturated fatty acids influences the liver structural recovery and hepatocyte binuclearity in female Wistar rats in experimental cirrhosis induced by thioacetamide. Exp Toxicol Pathol. 57:65-75.

Galisteo M., Sua'rez A., Montilla M.P., Fernandez M.I., Gil A. and Navarro M.C. (2006): Protective effects of Rosmarinus tomentosus ethanol extract on thioacetamide-induced liver cirrhosis in rats. Phytomedicine. 13:101-108.

Gill M.P.S. (2013): Comparative study of serum gamma glutamyltransferase, 5 'nucleotidase and alkaline phosphatase in icteric and an-icteric biliary disease patients. IMJM. 12(1):59-62.

Hadi N.R., Swadi A.A. and Mohammad M.I. (2012): Hepatoprotective Potential of Metformin against Methotrexate Induced Hepatotoxicity. ASIAN J. EXP. BIOL. SCI. 3(1): 110 - 117.

Helewski,K.J., Kowalczyk-Ziomek, G. I., Czecior, E., et al. ( 2010).Administration of low doses of TNF $\alpha$ protects rat liver from ischemic damage and re-perfusion injury. J. Physiol. Pharmacol. 61:273-278.

Hirsch C., Zouain C.S., Alves J.B., and Goes A.M. (1997): Induction of protective immunity and modulation of granulomatous hypersensitivity in mice using PIII, an anionic fraction of Schistosoma mansoni adult worm. Parasitol. 56 115: 21.

Huang H.C., Wang S.S., Chan C.Y., Chen Y.C., Lee F.Y., Chang F.Y., Chu C.J., Lin H.C., Lu R.H. and Lee S.D. (2007): Role of hepatic nitric oxide syntheses in rats with thioacetamide induced acute liver failure and encephalopathy. J Chin Med Assoc. 760:16-23.

Jacotot E, Costantini P, Laboureau E, Zamzami N, Susin SA, Kroemer G. Mitochondrial membrane permeabilization during the apoptotic process. Ann N Y Acad Sci. 1999;887:18-30

Joshi S.R. (2005): Metformin: Old wine in new bottle-evolving technology and therapy in diabetes. J Assoc Physicians India. 53: 963-72.

Khouri H., Collin F., Bonnefont-Rousselot D., Legrand A., Jore D. and GardèsAlbert M. (2004): Radical-induced oxidation of metformin. Eur J Biochem. 271(23-24): 4745-52

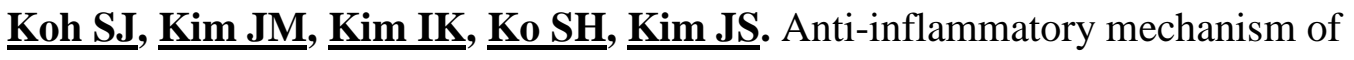
metformin and its effects in intestinal inflammation and colitis-associated colon cancerJ Gastroenterol Hepatol. 2014 Mar; 29 (3):502-10. 
Lamar J.M. (2011): Mastering the Trichrome stain, In: Special stains education guide, Second Edition, edited by G. L. Kumar and J. A. Kiernan, chapter 10; Dako, California, USA. pp, 93-97.

Low Y.Y., Leow C.K., Salto T.M., and Chung M.C.M. (2004): A proteomic analysis of thioacetamide-induced hepatotoxicity and cirrhosis in rat livers. Proteomics. 4: 3960-3974.

Madani H., Talebolhosseini M., Asgary S. and Naderi G.H. (2008): Hepatoprotective activity of Silybium marianum and Cichorium intybus against thioacetamide in rat. Pak J Nutr. 7(1):172-176.

Missima, F., Pagliarone, A.C., Orsatti, C.L., Bachiega, T.F., Sforcin, J.M.

2009. Ethnopharmacol. Sep 7;125(2):230-3. doi: 10.1016.

Muriel P., Quintanar M.E. and Perez-Alvarez W. (1993): Effect of colchicine on acetaminophen induced liver damage. Liver. 13:221-271.

Nishikim M., Roa N.A. and Yogi K. (1972): Biochem. Bioph. Res. Common. 46: 849854.

Ohkawa H., Ohish W. and Yagi k. (1979): Assay of lipid peroxide. Anal Biochem. pp 662-667.

Palomba S., Falbo A., Zullo F. and Orio F.J. (2009): Evidence based and potential benefits of metformin in the polycystic ovary syndrome: a comprehensive review. Endocr Rev. 30(1):1-50.

Park S.Y., Shin H.W., Lee K.B., Lee M.J., and Jang J.J. (2010): Differential expression of matrix metalloproteinases and tissue inhibitors of metalloproteinases in thioacetamide-induced chronic liver injury. J Korean Med Sci. 25(4): 570-576.

Rahn S.B. (2001): Liver Biopsy interpretation in chronic hepatitis. J Insur Med. 33:110-113.

Riddell R.H. (1982): Pathology of drug induced and toxic diseases. $1^{\text {st }}$ edition. Churchill Livingstone, NY. London.

Zhou G., Myers R., Li Y., Chen Y., Shen X., Melody J.F., et al. (2001): Role of AMP-activated protein kinase in mechanism of metformin action. J Clin Invest .108:1167-1174. 


\section{ميتفورمين يقلل التسمم الكبدى المحدث بواسطة ثيو أسيتاميد فى فئران التجارب}

\section{للسادة الاكاتزة}

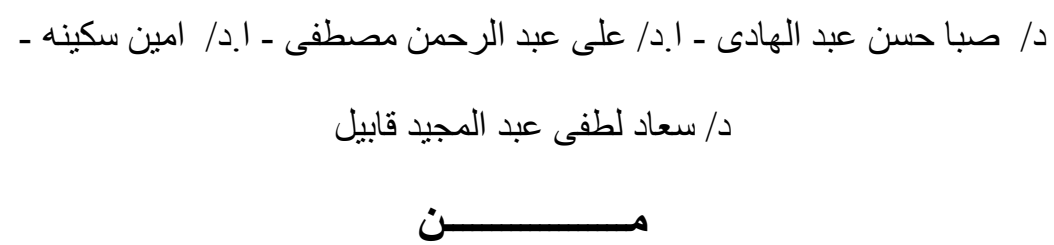

$$
\text { قسم الفارماكولوجيا الاكلينيكيه ــ كليه طب الزقازيق }
$$

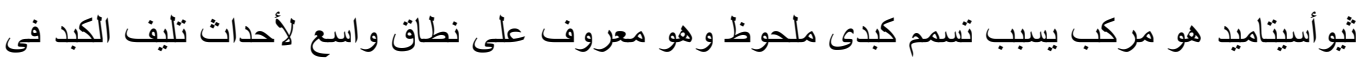

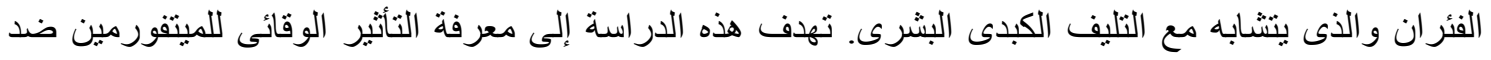

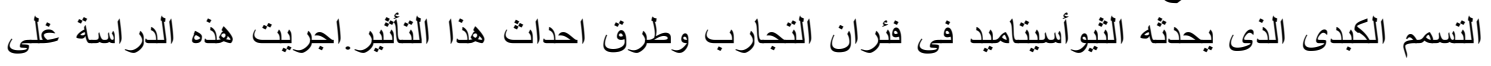

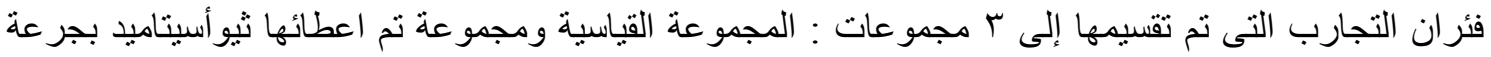

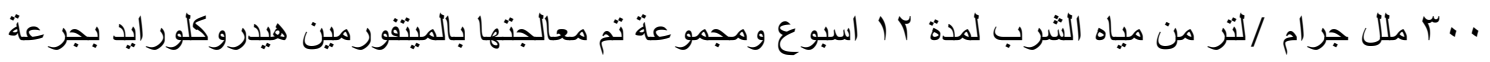

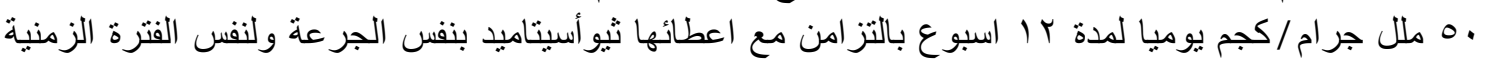

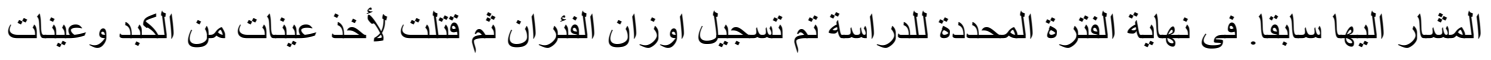

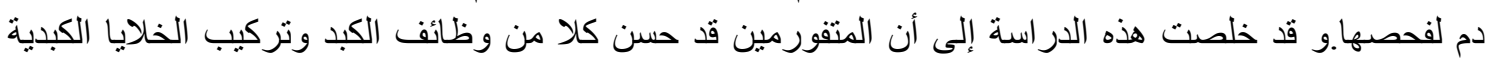

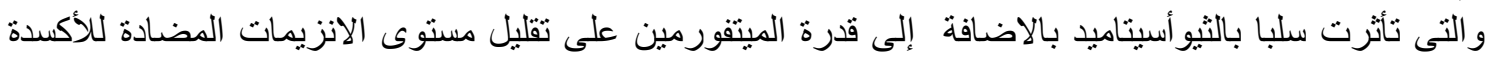

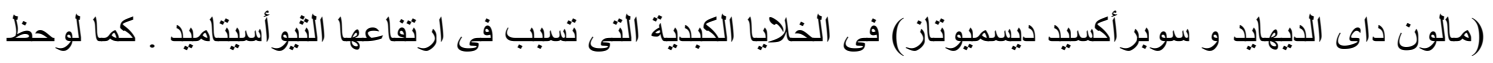

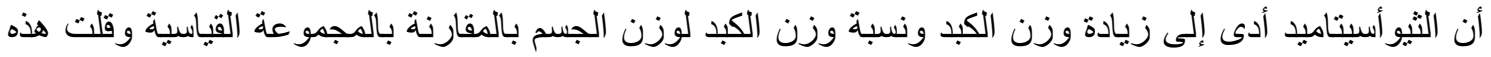

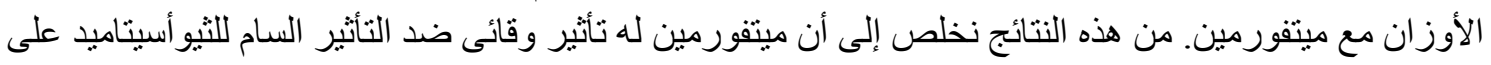
الكبد ويرجع ذللك لتأثيره المضاد للأكسدة من هذه النات 